\title{
Relações mútuas entre informação e conhecimento: o mesmo conceito?
}

\author{
Rodolfo Coutinho Moreira Xavier \\ Mestrado em ciência da informação - PUC-Campinas. \\ Graduado em filosofia com licenciatura plena em filosofia \\ - Unicamp. Graduado em economia - PUC-Campinas. SP, \\ Brasil. \\ E-mail: almeida.azevedo@hotmail.com
}

\author{
Rubenildo Oliveira da Costa \\ Mestre em ciência da informação/PUC-Campinas. \\ Bacharel em ciência da informação com habilitação em \\ biblioteconomia/PUC-Campinas. Vinculado à Biblioteca \\ Central Cesar Lattes da Unicamp, SP, Brasil. \\ E-mail: rubcosta@unicamp.br
}

\section{Resumo}

A proximidade entre os conceitos de informação e conhecimento provoca desordem conceitual em estudos na ciência da informação. Em contrapartida, o estabelecimento científico de uma disciplina depende de clareza conceitual acerca de seu objeto de estudo. Em vista disso, a hipótese proposta demonstra a necessidade de se mapearem as relações conceituais existentes entre informação (objeto de estudo da área) e conhecimento, objetivando evidenciar a distinção destes, para que possam ser usados com menos ambiguidade pelos pesquisadores da área. Para tanto, discutem-se, primeiramente, os conceitos de ciência da informação e de seu objeto de estudo, sob três paradigmas propostos por Capurro: fisicista, cognoscente e social; em seguida, algumas relações conceituais entre informação e conhecimento e suas consequências - existem relações de semelhança entre ambos, mas isso não faz com que se tornem idênticos. Definições anteriores sobre tais termos podem já ter constatado essas relações, contudo raramente esse assunto foi tratado de maneira pontual e com atenção, na falsa justificativa de que é um debate puramente teórico e que não levaria a resultado útil algum.

\section{Palavras-chave}

Informação. Conhecimento. Ciência da Informação. Epistemologia. Paradigma científico.

Ci. Inf., Brasília, DF, v. 39 n. 2, p.75-83, maio/ago., 2010

\author{
Mutual relations between information and \\ knowledge: do they are same concept
}

\begin{abstract}
The proximity between information and knowledge concepts causes conceptual disorder in Information Science studies. On the other hand, the establishment of a scientific discipline depends of the conceptual clarity about its study object. In view of this, the proposal hypothesis demonstrates the necessity to map the conceptual relations between information (area study object) and knowledge, aiming to show the distinction of these, to be used with less ambiguity by researchers. Thus, it discusses, first, the Information Science concepts and its study object, under three paradigms proposed by Capurro, following: physical, social and cognoscente, finally, some relations conceptual between information and knowledge and their consequences - there are similarity relations between them, but that does not mean that they become identical. Previous definitions of such terms may have found these relationships, however, rarely the subject was dealt with off and carefully, in the justification false of that debate is purely theoretical and do not lead to any useful result.
\end{abstract}

\section{Keywords}

Information. Knowledge. Information Science. Epistemology. Scientific paradigm.

\section{INTRODUÇÃO}

Discutem-se, primeiramente, os conceitos de ciência da informação (CI) e de seu objeto de estudo, sob três paradigmas propostos por Capurro (2003): fisicista, cognoscente e social; em seguida, algumas relações conceituais entre informação e conhecimento e suas consequências - existem relações de semelhança entre ambos, mas isso não faz com que se tornem idênticos.

O desenvolvimento de um debate sobre os conceitos de informação e conhecimento e suas relações foi sempre controverso na história da CI. Quando 
se discute sobre problemas de ordem abstrata, a primeira impressão é que não se pode chegar a conclusões gerais, compartilhadas e aceitas por todos, dado que as definições sugeridas podem variar sem se desviarem da verdade.

Que existam algumas definições e relações válidas para informação e conhecimento não significa que toda e qualquer definição ou relação seja válida, o que sugere que existe um núcleo comum de princípios aceito por todos nessa questão.

Por exemplo: se é possível chegar a certo consenso terminológico sobre informação e conhecimento com o uso das regras lógicas pelos debatedores, ambos estarão submetidos a essas regras como a proibição de se contradizer. Todos no debate acreditam que estão se referindo a uma realidade concreta e não simplesmente linguística e discursiva, creem ser possível com o uso das regras da razão entender o mundo como ele efetivamente é, pois o mundo traz nele a coerência lógica.

A negação desses princípios implica que não é útil continuar a discussão, pois se ela não é regida pela coerência, consistência de demonstrações lógicas e não acredita que se pode conhecer de fato as coisas como realmente são não merece continuidade, devido a sua falta de resultados relevantes e úteis decorrentes de um procedimento no mínimo duvidoso, para não dizer equivocado.

Haja vista o proposto, parte-se de princípios para se chegar a pontos comuns das regras do debate aos conceitos de informação e conhecimento e suas relações mútuas.

\section{O CONCEITO DE INFORMAÇÃO NA CIÊNCIA DA INFORMAÇÃO}

A discussão das relações entre informação e conhecimento na CI requer, primeiramente, outra abordagem acerca dos conceitos da própria área e seu objeto - a informação -, com a pretensão de vislumbrar os porquês da dificuldade do estabelecimento científico dos conceitos.
A explosão da informação e o contexto tecnológico foram as causas do surgimento da CI em meados do século XX, impulsionada posteriormente pelo valor atribuído ao conhecimento na sociedade da informação. Utilizando-se das práticas bibliotecárias e, principalmente, dos fundamentos da documentação de Otlet (1895), têm sido encontrados obstáculos em seu fundamento científico, uma vez que são exigidas teorias e definição clara de seu objeto de estudo.

Aqui reside o problema da CI: primeiramente por ser uma disciplina interdisciplinar, depois por ter características de uma ciência pós-moderna e, por último, pelo fato de possuir um objeto de estudo complexo e abstrato, características das ciências humanas e sociais. Nessa perspectiva, tentar-se-á daqui em diante discutir respectivamente esses três aspectos da disciplina.

Baseado nos principais problemas informacionais de origem social enfrentados pela CI, o teórico Saracevic (1995) a define como um campo dedicado ao questionamento científico e prática profissional com relação aos problemas de comunicação efetiva de conhecimento e arquivo de conhecimento entre humanos no contexto de uso social, institucional e/ ou individual e necessidade de informação.

Para ele, esses problemas que deram origem ao conceito de CI, por serem complexos, não podem ser resolvidos dentro de uma só disciplina. Por isso, a área é interdisciplinar por natureza, ou seja, nasceu assim, e suas principais interfaces são com as seguintes disciplinas: biblioteconomia, ciência da computação, ciências cognitivas (incluindo inteligência artificial) e comunicação.

Porém, ao analisar o seu conceito de CI, mais especificamente quando cita como características da área o questionamento científico, prática profissional e comunicação efetiva de arquivos de conhecimento, comparando-o com a afirmação de Shera (1980) de que a biblioteconomia é uma espécie de laboratório da CI, juntamente com a constatação da predominância na área da pesquisa empírica (estudo de caso) em detrimento da teórica (GOMES, 2006), poder-se-ia inferir que 
a interdisciplinaridade na CI se dá em torno de resolução de problemas concretos em ambientes informacionais (por exemplo, bibliotecas), não havendo, assim, construção teórica consistente nem troca recíproca com outras disciplinas com as quais faz interface.

Nesse sentido, várias fragilidades são apontadas em relação à questão da interdisciplinaridade da CI. Para Ingwersen (1992), a reciprocidade entre a CI e outras disciplinas, ou melhor, a relação de importarexportar ideias da área parece desequilibrada, ao passo que "enquanto é provavelmente verdade que importamos muitas teorias, pontos de vista e metodologias de outras disciplinas, deve-se também admitir que frequentemente transformamos estes investimentos em vantagem para nós.” Ou seja, nesse ponto de vista, a disciplina, em certa medida, importa conceitos e teorias, de outras área, porém não lhes oferece retorno.

Outra fragilidade é apontada por Pinheiro (2002). Segundo ela, a natureza interdisciplinar de uma área requer a disciplinaridade, em que se definem suas fronteiras constituintes, que, por sua vez, determinarão seus objetos materiais e formais, seus métodos, conceitos e teorias. Assim, supõese que devido ao fato da quase inexistência de trabalho teórico na CI e, consequentemente, poucos conceitos e teorias, a CI ainda não possui disciplinaridade, o que enfraquece a relação com outras áreas, as quais podem até suprimi-la.

A falta de estudos nessa linha e, mesmo, a presença incipiente de teóricos, mantém a ciência da informação em um estado de fragilidade teóricoconceitual (PINHEIRO e LOUREIRO, 1995). Para eles, tem sido assinalada a ausência, de um corpo de fundamentos teóricos que possa delinear o seu horizonte científico, e ainda se encontra em construção a epistemologia da ciência da informação ou a investigação dos conhecimentos que a permeiam.

Contudo, tem-se observado esforços recentes de pesquisadores teóricos brasileiros nesse sentido, haja vista os trabalhos apresentados nos últimos Enancibs (Encontros Nacionais de Pesquisa em Ciência da Informação).

Mesmo assim, acredita-se que está sendo árdua a complexa construção da epistemologia da CI, talvez por conta da interdisciplinaridade. Como visto, o estado de fragilidade teórico-conceitual da área dificulta vislumbrar seu horizonte científico. Essa situação parece provocar um entendimento superficial da área por parte dos pesquisadores advindos de outras áreas, resultando na dificuldade de construção de interfaces com suas áreas de origem. Se a interdisciplinaridade quer dizer troca entre as disciplinas, como a CI trocará algo se desconhece suas fronteiras?

Sabe-se que a pesquisa empírica, em geral, não cria fundamentação teórico-conceitual para a área, decorrendo na dificuldade de concepção e delimitação de seu objeto de estudo - a informação. Parece que a busca teórica em outros campos científicos pela CI (interdisciplinaridade) tem sido pouco produtiva. Pode ser mais apropriado afirmar que a interdisciplinaridade na área é mais prática do que teórica.

Essa situação leva alguns autores, dentre eles Dias (2000), a entendê-la como uma especialidade de uma área maior denominada Library and Science Information, ao contrário do que pensa Saracevic (1995) ao afirmar que "biblioteconomia e ciência da informação são dois campos diferentes com uma forte relação interdisciplinar, não sendo um mesmo campo, ou uma sendo parte ou um caso especial da outra."

Entretanto, na visão de Wersig (1993), a fragilidade teórico-conceitual-metodológica da CI, descrita anteriormente, estaria relacionada ao protótipo de um novo tipo de ciência - uma ciência pós-moderna. Nesse sentido, a CI seria uma ciência diferente das ciências clássicas ou modernas, dirigida pela busca do entendimento completo de como funciona o mundo, com métodos e objetos únicos, em que se desenvolva uma teoria ou conjunto de teorias 
inter-relacionadas. Para ele, a área nunca alcançou status de ciência justamente porque pertenceria a um conjunto complexo de abordagens desenvolvidas recentemente, dirigida pela "necessidade de desenvolver estratégias para resolver, em particular, aqueles problemas que têm sido causados pelas ciências clássicas e pelas tecnologias." (WERSIG, 1993, p. 229, tradução nossa). Assim, teria que desenvolver algum tipo de sistema de navegação conceitual, em que não haveria uma teoria, mas

um arcabouço de conceitos científicos genéricos ou modelos de conceitos comuns reformulados que estão entrelaçados sob dois aspectos: como eles foram desenvolvidos e como eles podem ser unidos através do ponto de vista do problema do uso do conhecimento sob as condições pós-modernas da informatização. (WERSIG, 1993, p. 238-239, tradução nossa).

Portanto, a própria complexidade de seu objeto coloca a dificuldade de classificá-la entre as ciências humanas e sociais. Embora normalmente classificada no campo das ciências sociais, seu objeto requer "o estudo objetivo do conhecimento, não somente como um fenômeno cognitivo [humano] mas também como fenômeno social peculiar para evolução do homem." (ROBERTS, $1976^{1}$ apud PINHEIRO, 1999, p. 157). Ou seja, os fenômenos humano e social estariam sempre presentes na CI, conforme observado no conceito da área formulado por Saracevic (1995), o qual a compreende em um contexto de uso social, institucional e/ou individual de arquivos de conhecimento.

Em outras palavras, ao entender o objeto de estudo da CI - a informação - como um significado transmitido a um ser consciente (LE COADIC, 2004), ter-se-ia de encará-la como fenômeno sociocognitivo. Assim, primeiramente a disciplina pertenceria às ciências sociais, pois o pensamento na sociedade exige convenções (por exemplo, a língua em comum) para retirar o significado do

${ }^{1}$ ROBERTS, Norman. Social considerations towards a definition of Information Science. Journal of Documentation, v. 32, n. 4, p. 249257, Dec. 1976. significante. Posteriormente, pertence às humanas, pois o raciocínio para geração de conhecimento é individual, ou seja, de acordo com Barreto (1999), o conhecimento acontece na individualidade do indivíduo, manipulando sua sensibilidade e percepção no trato com a informação. Logo, nessa perspectiva, a CI é primeiramente social (convenções) depois humana (cognição).

Em contrapartida, Loreiro (1999, p. 74), referindose à visão de Wersig, afirma que a CI poderia se constituir como uma nova modalidade de produção de conhecimento, de modo a considerá-la "nem humana, nem social, mas heterológica, plural e inter-relacional quanto a multidimensionalidade dos saberes."

Eduardo Dias (2002, p. 87), entretanto, parece desconsiderar o entendimento da CI como protótipo de uma ciência pós-moderna. Segundo ele, a disciplina "é frequentemente caracterizada como uma disciplina emergente, o que apenas torna ainda mais difícil a tarefa de entendê-la"; e continua "[...] entretanto, qualquer área ou campo do conhecimento está em permanente definição, por natureza, de vez que é o conjunto de ideias e pessoas que nela circulam que determinam, no final, seu conceito."

Por fim, uma vez que já se discutiu o conceito de CI, sua natureza interdisciplinar, suas características de ciência pós-moderna e sua inserção nas ciências sociais, resta agora se discutir o seu objeto - a informação -, o que também não é tarefa menor.

A informação entendida como significado transmitido a um ser consciente tem uma característica sociocognitiva, como visto anteriormente, e não somente a característica cognitiva como sugere a visão cognitivista presente na CI desde a década de 1980, a partir da qual, segundo Capurro (2003), originouse a conhecida teoria do Estado Anômalo do Conhecimento (Anomalous State of Knowledge ASK), desenvolvida por Nicholas Belkin e outros

Ci. Inf., Brasília, DF, v. 39 n. 2, p.75-83, maio/ago., 2010 
(BELKIN 1980²; BELKIN; ODDY; BROOKS, $\left.1982^{3}\right)$. Tal teoria parte da premissa de que a busca de informação tem origem na necessidade que surge quando existe um estado de dúvida ou ASK, no qual o conhecimento que o usuário dispõe para resolver um problema não é suficiente.

Entretanto, Capurro (2003) critica esse enfoque cognitivo como idealista e individualista, o qual considera somente o sujeito cognoscente, deixando de lado os condicionamentos sociais e materiais do existir humano, ou seja, possui uma visão "associal". Nessa perspectiva, caberia a introdução de um novo paradigma na CI - o social -, no qual, segundo Capurro (2003), transformar-se-ia a teoria do estado cognitivo anômalo para o estado existencial anômalo.

Portanto, o objeto de estudo da CI compreende um enfoque sociocognitivo, quando considerado um significado transmitido a um ser consciente. Entretanto, existe outro enfoque - o físico -, que, aliás, foi o primeiro paradigma da área e muito criticado pelo cognitivo “associal”. Esse paradigma fisicista, segundo Capurro (2003), foi introduzido pela Teoria da Informação de Shannon e Weaver $\left(1949 / 1972^{4}\right)$, a qual consistia em uma analogia entre a veiculação física de um sinal e a transmissão de uma mensagem. Contudo, descartava o sujeito cognoscente e/ou o aspecto semântico, ou melhor, não considerava a assimilação da informação pelo receptor.

Em vista dessa crítica, a discussão do paradigma fisicista parece ter sido retomada com Buckland (1991) e sua informação-como-coisa (informationas-think). Nessa proposição, ao contrário de Shannon e Weaver, Buckland considera o aspecto semântico. Logo, considerando o aspecto intangível

\footnotetext{
2 BELKIN, Nicholas J. Anomalous States of Knowledge as Basis for Information Retrieval. The Canadian Journal of Information Science, v. 5, p. 133-143, 1980.

${ }^{3}$ BELKIN, Nicholas J.; ODDY, R.N.; BROOKS, H.M. ASK for Information Retrieval: Part I. Background and Theory. Journal of Documentation, v. 38, n. 2, p. 61-71, 1982.

${ }^{4}$ SHANNON, Claude; WEAVER, Warren. The mathematical theory of communication. Urbana, IL.: University of Illinois Press, 1949/1972.
}

da informação como aquela que reduz a incerteza (informação-como-conhecimento), o autor observa que para comunicá-la faz-se necessário expressá-la, descrevê-la ou representá-la de alguma maneira física, como um sinal, texto ou comunicação, ou seja, "qualquer expressão, descrição ou representação seria "informação-como-coisa".

É com informação nesse sentido que sistemas de informação lidam diretamente. [...] Pode ser que a intenção seja a de que usuários tornem-se bem informados (informação-como-processo) e o resultado desse processo poderia ser conhecimento (informação-como-conhecimento). Mas o significado, no entanto, que é manipulado e operacionalizado, que é armazenado e recuperado, é a informação física (informação-como-coisa). (BUCKLAND, 1991, p. 352, tradução nossa).

Buckland (1991) reconhece que esse tipo de informação é rejeitado por uma legião de teóricos da informação. Em vista disso, entretanto, conclui que "é mais provável que o exame da 'informaçãocomo-coisa" traga forma a esse campo amorfo e evite limitações baseadas nas tradições acadêmicas passadas." (BUCKLAND, 1991, p. 359, tradução nossa).

A partir do exposto, considera-se aqui que o conceito de informação de Barreto (1999) parece concordar com os três paradigmas de Capurro (2003): a informação é uma estrutura significante com competência e intenção de gerar conhecimento no indivíduo e em seu grupo, possibilitando seu desenvolvimento e bem-estar.

Assim, ao mencionar informação como estrutura, admite-se o paradigma fisicista, mas não no sentido de Shannon e Weaver, e sim no sentido de informação-como-coisa de Buckland. Ao citar o aspecto significante da informação, aceita-se o paradigma cognitivista. E, por último, ao fazer referência ao grupo no qual o indivíduo cognoscente atua, acolhe-se o paradigma social.

Por fim, acredita-se que tanto a CI quanto seu objeto de estudo encontram-se, portanto, entre o cristal e a chama, como bem mostra a analogia de Barreto (1999). O cristal estaria representando a 
'informação-como-coisa', as técnicas e os estoques de informação, enquanto a chama simbolizaria a assimilação da informação, processo cognitivo o conhecimento. Em suas palavras, "a informação há que deixar a beleza do cristal entesourado para consumir-se na chama das individualidades na semântica e na percepção". Capurro (2003) parece compartilhar do mesmo entendimento, ao afirmar que "a diferença entre mensagem, ou oferta de sentido, e informação, ou seleção de sentido é, a meu ver, a diferença crucial de nossa disciplina entendida assim como teoria das mensagens e não só como teoria da informação.” (grifo nosso).

\section{INFORMAÇÃO E CONHECIMENTO}

A informação e o conhecimento são simultaneamente causa e efeito um de si mesmos, numa interação dinâmica em que a sucessão pode ser plenamente invertida mas não gera nenhuma contradição, pois se é causa e efeito com relação a coisas diferentes em momentos distintos, quer dizer que se é causa só quando o outro é efeito e se é efeito apenas quando o outro for causa, gera assim expansão benéfica a ambos.

Disponibilizar informação é promover a geração de conhecimento, que por sua vez produzirá mais informação e assim sucessivamente; somente com uma política nacional de desenvolvimento em ciência e tecnologia, mas não só a partir dela, viabilizar-se-á manutenção desse fluxo.

Pode-se dizer que o conhecimento em sentido amplo se confunde com a própria definição de informação. O Dicionário Aurélio traz, dentre os vários sentidos atribuídos à informação, um que diz que informação é conhecimento, participação, ou seja, quando se tem informação sobre algo é como se houvesse conhecimento, como se soubesse do que se trata (AURÉLIO, 1999, p. 1109). Complementarmente, dentre os vários sentidos registrados na mesma fonte sobre conhecimento, um deles diz que conhecimento é informação, notícia, ciência (AURÉLIO, 1999, p. 529). Essa dependência do conhecimento com relação à informação faz com que seu mercado seja orientado pelos predicados que ela carrega. A informação é o material direto, matéria-prima que compõe o conhecimento. Nesse sentido, a cadeia produtiva do conhecimento passa, necessariamente, pela produção da informação, esta como uma interpretação mais verídica e comprovada possível de algum fato.

Não cabe a uma teoria do conhecimento voltada à CI observar que essas relações não existem, mas mapeá-las, dizer com maior precisão quais são elas e como se estabelecem, para que os conceitos possam ser utilizados com menos ambiguidade pelos pesquisadores e cientistas. Conhecimento e informação não são vocábulos exclusivos da CI, fazem parte da linguagem artificial de várias ciências e também da epistemologia, o que exige uma análise mais detida dos atributos essenciais de ambos os conceitos.

É necessário ter em mente que a informação científica que se oferece não carrega em si a simples função de informar uma inovação, ou qualquer outro assunto, mas tem a potencialidade latente de produzir conhecimento. Contudo, esse potencial só pode ser ativado por um indivíduo capaz e que coloca em exercício sua capacidade no momento de assimilação da informação.

Dessa maneira, deve-se sempre recordar que, quando se fala da venda de informação ou conhecimento indiscriminadamente, é porque a atribuição de relevância e utilidade da informação científica só será feita por profissionais capazes e instruídos, os quais podem extrair dessa informação o máximo predicado que ela carrega: disparar o desenvolvimento de novo conhecimento no ser humano. Muitos não chegam a tamanho feito, mas a utilidade da informação imputada pelo sujeito depende de que ele chegue nesse último e glorificante estágio de aquisição.

Toda a informação deseja cumprir ao máximo sua própria definição, seu conceito, busca a sua realidade na sua própria ideia, pois nela essa informação é mais perene, sobrevivendo mais no terreno das informações particulares e fugazes do mundo material. 
A ideia é como um paradigma, um modelo a ser seguido por qualquer informação; quanto mais a informação segue sua definição, mais ela realiza em si a própria essência, isto é, produzir conhecimento. Porém, isso não significa que a ideia é somente conceitual, abstrata, mas ela é real tanto quanto o objeto a que se refere: "Uma ideia é a plena realização de um conceito (o qual tampouco é uma entidade mental): uma ideia, é assim, verdadeira ou a verdade."( HEGEL ${ }^{5}$ apud INWOOD, 1997, p. 169).

Se inexistissem paradigmas, modelos ou ideais de informação a serem seguidos, não se saberia distinguir que informação é mais informação; qual informação é menos informação, qual é mais verdadeira, pois segue rigorosamente sua definição, e qual é mais falsa, pois se afasta dessa definição.

Só se pode conhecer as informações particulares reais porque tem-se em cada pessoa a definição de informação, como também todas as outras informações. Portanto, tudo só se realiza mais plenamente quando materializa sua essência no mundo, ou seja, aproxima-se da sua definição. Não só todos os entes materiais seguem essa regra, como também a informação, a qual sempre almeja ser mais aquilo que é essencialmente - conhecimento. Apesar de nunca alcançá-la absolutamente, tudo sempre deseja sua perfeição.

Isso significa dizer que os conhecimentos particulares que existem são transitórios e efêmeros: “[...] das coisas pertence a transitoriedade, ou seja, o fato de que nasçam, se modifiquem e pereçam.” (PLATÃO ${ }^{6}$ apud WEISCHEDEL, 1999, p. 54).

O ser da informação não está nas informações particulares, mas sim na sua definição, pois é só pela participação com ela que uma informação particular pode ser denominada informação. Qualquer informação particular será mais real dependendo

\footnotetext{
${ }^{5}$ HEGEl, Georg W.F. A Estética: a ideia e o ideal. São Paulo: Editora Nova Cultural Ltda., 1996. p. 128-135. (Coleção Os Pensadores). ${ }^{6}$ PLATÃO. A República. São Paulo: Editora Nova Cultural Ltda., 1997. (Coleção Os Pensadores).
}

Ci. Inf., Brasília, DF, v. 39 n. 2, p.75-83, maio/ago., 2010 da realidade que a definição lhe atribuir, ou seja, a realidade de qualquer informação advém da definição, do conceito de informação e não da sua simples materialização.

Conceituar ou significar implica estar dentro de uma cultura, é ela que abarca dentre seus exemplos e manifestações a informação e o conhecimento:

Por outro lado, a cultura não se caracteriza apenas pela gama de atividades ou objetos tradicionalmente chamados culturais, de natureza espiritual ou abstrata, mas apresenta-se sob a forma de diferentes manifestações que integram o vasto e intrincado sistema de significações (COELHO, 2004, p. 104).

As informações particulares são transitórias e fugazes, contudo a definição da informação permanece no tempo e no espaço, historicamente mutável, mas incorruptível; toda a informação quer escapar dessa efemeridade, tornando-se tão perene quanto sua definição: “a árvore quer ser tanto quanto possível árvore, o homem tanto quanto possível homem, a justiça, tanto quanto possível, justiça. Tudo aspira a realizar na existência a ideia característica" (PLATÃO ${ }^{7}$ apud WEISCHEDEL, 1999, p. 54).

Isso também vale para o conhecimento, mas como o conhecimento é parte importante da própria definição da informação, o entrelaçamento conceitual entre ambos faz com que, quando um se torna mais semelhante e igualado à sua definição, mais traz o outro para sua plena realização. Os conhecimentos de todos os tipos que existem querem ser tanto quanto possível mais perfeitos e realizados, idênticos à ideia de conhecimento em si: "a essência de uma planta, por exemplo, reside em pretender, portanto, perfazer-se na semente, na flor e no fruto." (ARISTÓTELES ${ }^{8}$ apud WEISCHEDEL, 1999, p. 64). Assim também o conhecimento quer ser mais conhecimento, quer se tornar informação e vice-versa.

\footnotetext{
${ }^{7}$ Idem 6.

${ }^{8}$ ARISTÓTELES. A Metafísica. São Paulo: Editora Nova Cultural Ltda, 1970. (Coleção os Pensadores).
} 
Quanto mais o conhecimento se aproxima de sua ideia em sentido lato, mais como efeito de um conjunto articulado de informações enaltece e realiza a essência de suas causadoras. Por conseguinte, quando se diz informação em si ou conhecimento em si, não se está dizendo que esses conceitos se definem apenas por si mesmos, sem exigir outros conceitos ao lado deles, pelo contrário, o conceito de informação depende do conceito de conhecimento, o qual pressupõe o conceito de informação e sua realização nas informações particulares para a própria existência: "As unidades linguísticas não são absolutos autossubsistentes isolados; possuem o que se chama identidade relacional. A palavra só existe porque se relaciona com outras palavras." (MGARRY, 1999, p. 20, grifo do autor).

Esses pontos tornam complicado o debate sobre qual a efetiva realidade da informação. Não basta que algo esteja gravado ou registrado em qualquer suporte material, faz-se necessário avaliar a qualidade, a utilidade, a relevância, o uso, a pertinência, a potencialidade de gerar conhecimento que essa informação carrega. Entretanto, uma informação particular ou singular pode ser a mais bem equipada em todos esses quesitos, mas caso não seja registrada, armazenada, organizada, selecionada e recuperada por suportes materiais e tecnológicos, não cumprirá no ser humano a realização da sua ideia. Porém, qualquer informação particular depende do entendimento de qualquer humano, ou seja, sem entendimento não se pode denominar qualquer informação particular de informação.

Por isso, faz-se necessário acrescentar à definição de informação um aspecto decisivo, para se enfatizar o imenso valor que a informação tem para os campos sociais, econômicos, políticos e humanos, que a informação é conhecimento no sentido amplo, ou seja, a formação na mente da ideia de algo ou uma simples identificação que está gravada em um suporte material, seja essa inscrição impressa, numérica, oral ou audiovisual (LE COADIC, 2004). Assim, exigem-se registro, armazenamento, tratamento, recuperação da informação para que seja útil e trabalhada na ciência e na indústria, pois sem sua preservação, manutenção, registro é inviável estudá-la, pesquisá-la e mercantilizá-la.

\section{CONSIDERAÇÕES FINAIS}

Os debates nessa área epistemológica e conceitual sempre prosseguem. Pode-se terminar um artigo, mas não se encerra a discussão em torno de um tema; ela continua, seja raramente abordada ou com frequência e entusiasmo.

As relações principais que se pode verificar entre informação e conhecimento são visíveis até na linguagem natural, a linguagem científica somente explica de modo mais convincente quais são essas relações, como elas se estabelecem e por que elas existem.

A informação é a matéria-prima do conhecimento, sem a qual o conhecimento não teria coesão suficiente para tornar-se conhecimento, dado que para que uma coisa exista é necessário que o insumo que a compõe mantenha sua unidade integrada, sua preservação e manutenção. Isso não ocorre apenas no que se refere aos suportes materiais para os documentos, mas também no que diz respeito aos conceitos e definições que compõem os conhecimentos.

Outro aspecto destacado é que a informação, à medida que alcança no sujeito o desenvolvimento pleno de todos seus predicados essenciais, deixa de ser mera informação, torna-se conhecimento. Isso significa que, quando algo se torna ao máximo a própria definição, deixa de ser só ele mesmo e passa a ser outra coisa, a coisa para a qual sua finalidade intrínseca a dirige realizando todas as suas capacidades.

Definições anteriores sobre conhecimento e informação podem já ter constatado essas relações, contudo, raramente esse assunto foi tratado de maneira pontual e com atenção, na falsa justificativa de que é um debate puramente teórico e que não levaria a resultado útil algum.

Inicia-se aqui esta discussão, acreditando que ela não trará só elucubrações vazias, mas contribuições reais de uma teoria do conhecimento que fundamente a prática e a teoria da CI.

Artigo submetido em 23/07/2009 e aceito em 22/02/2011.

Ci. Inf., Brasília, DF, v. 39 n. 2, p.75-83, maio/ago., 2010 
Relações mútuas entre informação e conhecimento: o mesmo conceito?

\section{REFERÊNCIAS}

BARRETO, Aldo de A. Os Destinos da Ciência da Informação: entre o cristal e a chama. Informação e Sociedade: estudos, João Pessoa, v. 9, n. 2, p. 371-382, 1999.

BUCKLAND, Michael K. Information as thing. Journal of the American Society for information Science (JASIS), v. 42, n. 5, p. 351-360, 1991.

CAPURRO, Rafael. Epistemologia e Ciência da informação. In: V ENCONTRO NACIONAL DE PESQUISA EM CIÊNCIA DA INfORMAÇÃO, 5., Belo Horizonte, 2003. Anais... Belo Horizonte: Escola de Ciência da Informação da UFMG, 2003. 1 cd-rom.

COELHO, José T. Dicionário crítico de Política Cultural. São Paulo: Editora Iluminuras LTDA, 2004.

DIAS, Eduardo W. Biblioteconomia e ciência da informação: natureza e relações. Perspectivas em Ciência da Informação, v. 5, n. especial, p. $67-$ 80, jan./jun. 2000.

O especifico da ciência da informação. In: AQUINO, Mirian de A. (org.). O campo da Ciência da Informação: gênese, conexões e especificidade. João Pessoa, PB: UFPB, 2002. p. 87-99.

FERREIRA, Aurélio B. H. O dicionário da língua portuguesa. Rio de Janeiro. Editora Nova Fronteira, 1999.

GOMES, Maria Y.F.S. de F. Tendências atuais da produção científica em Biblioteconomia e Ciência da Informação no Brasil. DataGramaZero - Revista de Ciência da Informação, v. 7, n. 3, Jun. 2006.

INGWERSEN, Peter. Conceptions of Information Science. In.: VAKKARI, P. CRONIN, B. (Ed.) Conceptions of Library and Information Science: historical, empirical and theoretical perspectives. London: Taylor Graham, 1992. p. 299-312.

INWOOD, Michael. Dicionário Hegel. Rio de Janeiro: Jorge Zahar Editor, 1997.
LE COADIC, Yves-François. A Ciência da Informação. 2.ed. Brasília: Briquet de Lemos, 2004. 124 p.

LOUREIRO, José M.M. Ciência da informação: nem ciência social, nem humana, apenas uma ciência diferente. In: PINHEIRO, Lena V.R. (Org.). Ciência da informação, Ciências Sociais e interdisciplinaridade. Brasília; Rio de Janeiro: IBICT, 1999. p. 65-77.

MGARRY, Kevin. O contexto dinâmico da informação: uma análise introdutória. Brasília: Briquet de Lemos, 1999

PINHEIRO, Lena V.R. Campo interdisciplinar da ciência da informação: fronteiras remotas e recentes. In: PINHEIRO, Lena V.R. (Org.). Ciência da informação, Ciências Sociais e interdisciplinaridade. Brasília; Rio de Janeiro: IBICT, 1999. p. 155-182.

Gênese da ciência da informação ou sinais anunciadores da nova era. In: AQUINO, Mirian de A. (Org.). O campo da ciência da informação: gênese, conexões e escificidade. João Pessoa, PB: UFPB, 2002. p. 61-85.

; LOUREIRO, José M.M. Traçados e limites da ciência da informação. Ciência da Informação, Brasília, v. 24, n. 2, p. 132-142, maio/ago. 2004.

SARACEVIC, Telfo. Interdisciplinary nature of information science. Ciência da Informação, v. 24, n. 1, p. 36-41, 1995.

SHERA, Jessé H. Sobre biblioteconomia, documentação e ciência da informação. In: GOMES, Hagar E. (Org.). Ciência da informação ou informática. Rio de Janeiro: Calunga, 1980. p. 91-105. (publicado originalmente pela Boletin de la Unesco para las Bibliotecas, Paris, v. 22, n. 2, p. 58-63, mar./abril. 1968).

WEISCHEDEL, Wilhelm. A Escada dos Fundos da Filosofia. São Paulo: Editora Angra LTDA, 1999.

WERSIG, Gernot. Information science: the study postmodern knowledge usage. Information processing and Management, v. 29, n. 2, p. 229-239, 1993. 